\title{
USE OF DOPAMINE AGONIST IN TETANUS SPASMS - A NOVEL APPROACH TO REVERT THE RESPIRATORY SPASM - THE CAUSE OF MORTALITY
}

\author{
VINOD KUMAR ${ }^{1}$, ABHISHEK GUPTA ${ }^{1}$, DEVESH JOHARI ${ }^{1}$, and LORI TEWARI ${ }^{1}$ \\ ${ }^{1}$ ADVANCE NEURO AND GENERAL HOSPITAL
}

July 1, 2020

\begin{abstract}
In tetanus patients Levodopa and Carbidopa combination (which is usually used to relieve the signs of extrapyramidal) causes respiratory muscles spasm relief thereby the need for sedatives is decreased and patient saved later on via central nervous system mechanism, by providing the inhibitory neurotransmitters at Anterior Horn cells.
\end{abstract}

Keywords

Tetanus; Combination of Levodopa and Carbidopa; Respiratory muscle spasm relief.

KEY CLINICAL MESSAGE:

Combination of LEVODOPA and CARBIDOPA relieves the respiratory muscle spasm in tetanus which is the main cause of the death.

ETHICAL STATEMENT

NOT NEEDED SINCE THIS DRUG IS BEING USED IN HUMANS FOR PARKINSONISM AND TO TREAT TREMORS

$M A N U S C R I P T$

USE OF DOPAMINE AGONIST IN TETANUS SPASMS - A NOVEL APPROACH TO REVERT THE RESPIRATORY SPASM - THE CAUSE OF MORTALITY

Introduction:

Tetanus (Bacterium Clostridium tetani), also called as lockjaw or trismus, produces toxin which interferes with muscle contractions, is fatal by virtue of its respiratory muscle spasm ${ }^{1}$. Most commonly the spasms begin in the jaw for few minutes each time for three to four weeks ${ }^{2}$. Spasms may be so severe that bone fractures may occur ${ }^{3}$. The spasms can also affect the facial muscles resulting in an appearance called risus sardonicus. Chest, neck, back, abdominal muscles, and buttocks may be affected. Back muscle spasms often cause arching, called opisthotonos. With treatment about $10 \%$ of people who contract tetanus die ${ }^{1}$. Death can occur within four days.

Pathophysiology of tetanus spasms:

The tetanus toxin initially binds to peripheral nerve terminals then it retrogradely goes to CNS attaches with gangliosides at presynaptic inhibitory motor nerve endings, blocks glycine and gamma amino butyric acid (GABA) across the synaptic cleft. Thus, the excitatory impulses are out of control by any excitatory 
impulse. The generalized muscular spasms characteristic of tetanus is produced. The toxin appears to act by selective cleavage of a protein component of synaptic vesicles, synaptobrevin II, and this prevents the release of neurotransmitters by the cells ${ }^{4}$.

The mortality in tetanus is high if patient experiences respiratory spasms. But patient doesn't get spasms (especially respiratory spasms) since the start of disease process. This means the inhibitory glycine and GABA or dopamine across the synaptic cleft from cerebellum, midbrain and basal ganglia controls the agonist and antagonist muscle via its regulatory factors, which inhibits the spasm since the start of disease. With increasing amount of toxin from the bacteria these neurotransmitters get depleted. When this store gets exhausted, the spasm gets clinically evident, in the form of opisthotonos and later respiratory muscle spasm and eventually death.

As we know dopamine is being synthesized in Substantia Nigra and Red Nucleus region of Midbrain and then travels via Striatonigral pathway to basal ganglia and also to cerebellum. From where it travels down to Renshaw cells in the Anterior Horn Cells of spinal cord and regulates the overexcitotory impulses causing decrease in spasm. Thus, this circuit is just the natural circuit of body which is being used to suppress the spasm naturally. So, by giving centrally acting dopamine agonists (Levodopa with carbidopa) the natural body's inhibitory neurotransmitter store is restored to normal which causes decrease in respiratory spasms and saves life. This single pilot case study hypothesizes the fact that with the supply of these neurotransmitters (dopamine) the spasm should get relieved immediately and thus the life saved. We have used the combination of carbidopa and levodopa to these patients to decrease the spasms specially the respiratory spasm which is the main cause of death in tetanus cases.

Passive immunization with human tetanus immune globulin (TIG) shortens the course of tetanus and may lessen its severity. A dose of $500 \mathrm{U}$ may be as effective as larger doses. Therapeutic TIG (3,000-6,000 units as 1 dose) has also been recommended for generalized tetanus ${ }^{5}$.

Case report:

A female of 28 years with history of left leg bullock cart injury admitted in emergency, having fever and multiple skeleton muscle spasms, specially lockjaw and opisthotonos. She was kept in tetanus ward and managed conservatively in dark room for $24 \mathrm{hrs}$ with high dose sedatives (Diazepam), antibiotics and antipyretic measures with debridement and dressing of wound done, ATS was also given. Then waited for 24 hours until now she continuously presented with lockjaw and multiple respiratory muscle spasm.

Then we put Ryle's tube and dopamine agonists in the form of Levodopa and carbidopa combination (Syndopa $275 \mathrm{mg}$ ) given. The muscle spasm, a characteristic feature of tetanus, is much relived. The patient got relief not only in exhaustion but also regained smooth respiration. This treatment continued for 2 to 3 weeks till normal knee and ankle jerks and stabilization of patient.

After 3 weeks patient was discharged with no residual tetanic spasm and then Syndopa was stopped.

Since this is the pilot study in a single case with excellent result, we are planning to study with more cases.

\section{CONCLUSION}

The combination of Levodopa and Carbidopa is highly effective to relive various muscular spasm especially respiratory spasm, which is the main cause of death in these cases.

\section{ACKNOWLEDMENT AND CONTRIBUTIONS OF ALL THE AUTHORS}

1. DR VINOD KUMAR: MAIN CORESPONDENCE AUTHOR

2. DR ABHISHEK GUPTA: MAIN ASSISTANT TO DR VINOD KUMAR TO WRITE THIS PAPER

3. DR DEVESH JOHARI: INDEPENDENT CLINICIAN TO JUDGE THE RABIES PATIENT

4. MISS LORI TEWARI: TO COLLECT ALL THE DATA

We are extremely thankful to Prof Dr (LATE) H K Das Gupta Sir for giving us permission to use the Levodopa and Carbidopa combination on tetanus patients. 


\section{REFERENCES}

1. Tetanus (PDF). CDC Pink Book. Retrieved 2007-01-26

2. Atkinson, William (May 2012). Tetanus Epidemiology and Prevention of Vaccine-Preventable Diseases (12 ed). Public Health Foundation. Pp. 291-300. ISBN 9780983263135. Retrieved 12 Feb 2015.

3. Tetanus Symptoms and Complications. cdc.gov. January 9, 2013. Retrieved 12 February 2015.

4. http://textbookofbacteriology.net/themicrobialworld/Tetanus.html.

5. Tetanus-Puerto Rico, 2002. MMWR Morb Mortal Wkly Rep . 2002 Jul 19. 51(28):613-5. 